\title{
Conductivity and structure of sub-micrometric SrTiO3-YSZ composites
}

Ruiz Trejo, Enrique; Thydén, Karl Tor Sune; Bonanos, Nikolaos; Mogensen, Mogens Bjerg

Published in:

Solid State lonics

Link to article, DOI:

10.1016/j.ssi.2016.01.040

Publication date:

2016

Document Version

Peer reviewed version

Link back to DTU Orbit

Citation (APA):

Ruiz Trejo, E., Thydén, K. T. S., Bonanos, N., \& Mogensen, M. B. (2016). Conductivity and structure of submicrometric $\mathrm{SrTiO}_{3}-\mathrm{YSZ}$ composites. Solid State lonics, 288, 82-87. https://doi.org/10.1016/j.ssi.2016.01.040

\section{General rights}

Copyright and moral rights for the publications made accessible in the public portal are retained by the authors and/or other copyright owners and it is a condition of accessing publications that users recognise and abide by the legal requirements associated with these rights.

- Users may download and print one copy of any publication from the public portal for the purpose of private study or research.

- You may not further distribute the material or use it for any profit-making activity or commercial gain

- You may freely distribute the URL identifying the publication in the public portal 


\title{
Conductivity and structure of sub-micrometric $\mathrm{SrTiO}_{3}$-YSZ composites
}

\author{
E Ruiz-Trejo $^{1}$, K. Thyden, N. Bonanos, M. B. Mogensen
}

Department of Energy Conversion and Storage, Technical University of Denmark, Risø Campus, Frederiksborgvej 399, DK-4000 Roskilde, Denmark.

\section{$\underline{\text { Abstract }}$}

Sub-micrometric composites of $\mathrm{SrTiO}_{3}$-YSZ (1:1 volume) and samples of $\mathrm{SrTiO}_{3}$ were prepared by high temperature consolidation of precursors obtained by precipitation with $\mathrm{NaOH}$. The structure development and morphology of the precursors were studied by XRD and SEM. The perovskite and fluorite phases in the composites are clearly formed at $600{ }^{\circ} \mathrm{C}$ with no signs of reaction up to 1100 ${ }^{\circ} \mathrm{C}$; the nominally pure $\mathrm{SrTiO}_{3}$ can be formed at temperatures as low as $400{ }^{\circ} \mathrm{C}$. Composites with submicrometric grain sizes can be prepared successfully without reaction between the components, although a change in the cell parameter of the $\mathrm{SrTiO}_{3}$ is attributed to the presence of Na.

The consolidated composites were studied by impedance spectroscopy between $200-400{ }^{\circ} \mathrm{C}$ and at a fixed temperature of $600{ }^{\circ} \mathrm{C}$ with a scan in the partial pressure of oxygen. The composites did not exhibit high levels of ionic conductivity in the grain boundary nor the bulk. The conductivity of Nafree composites shows lower levels of conductivity than pure YSZ, while samples with Na showed increased conductivity. The conductivity of $\mathrm{SrTiO}_{3}$ exhibited an enhancement attributed to p-type conductivity, although contributions from protons cannot be disregarded as some Na doping is present.

\footnotetext{
${ }^{1}$ Present address: Department of Earth Science and Engineering, Imperial College London, SW7 2AZ, UK, eruiztre@imperial.ac.uk
} 


\section{Keywords}

$\mathrm{SrTiO}_{3} / \mathrm{YSZ}$ composites, Na-doped $\mathrm{SrTiO}_{3}$, conductivity in composites

\section{Introduction}

An unprecedented increase in oxygen ion conductivity in intercalated structures of $8 \% \mathrm{Y}_{2} \mathrm{O}_{3}$ doped $\mathrm{ZrO}_{2}$ (YSZ) and $\mathrm{SrTiO}_{3}$ was reported a few years ago by Garcia-Barriocanal et al [1]. If the conductivity of one of these heterostructures is extrapolated to room temperature a difference of ca. 8 orders of magnitude compared to standard YSZ is found. These findings were followed by serious criticism $[2,3,4]$ : one of the main objections being that $\mathrm{SrTiO}_{3}$ can exhibit p-type conductivity.

Conductivity enhancement has been reported before in heterolayers of $\mathrm{CaF}_{2} / \mathrm{BaF}_{2}$ very much in accord with space charge theory [5]. The possibility of conductivity enhancement in $\mathrm{YSZ} / \mathrm{Ln}_{2} \mathrm{O}_{3}$ interfaces has been discussed in [3] where the authors argue that the strain at the interface, dilative or compressive, can lead to enhancement or decrease of the oxygen mobility, respectively. On the other hand, other groups have found no indication of oxygen mobility in similar systems [6] or even indicated that the conductivity is dominated by $\mathrm{SrTiO}_{3}$ [7].

Despite the current disagreement on the nature of the conductivity in $\mathrm{SrTiO}_{3}$-YSZ interfaces there is further interest on composites of these two materials as they represent alternative anodes for fuel cells: $\mathrm{SrTiO}_{3}$ can exhibit high electronic conductivity achieved by suitable doping and high temperature reduction treatment $\left(>1300^{\circ} \mathrm{C}\right)[8,9,10]$.

The objectives of this work are then: To present a novel fabrication method for composites of $\mathrm{SrTiO}_{3}$ and YSZ and to study the electrical properties of samples with a large interfacial contact between the two phases. Should a large effect exist as reported in [1], then it might be possible to detect it in 3dimensional systems where a large number of $\mathrm{SrTiO}_{3}-\mathrm{YSZ}$ interfaces exist. 


\section{Experimental}

\subsection{Synthesis of nanocrystalline $\mathrm{SrTiO}_{3}$ and $\mathrm{YSZ}$}

A batch of $\mathrm{SrTiO}_{3}$ and several batches of $\mathrm{SrTiO}_{3} / \mathrm{YSZ}$ (1:1 volume unless otherwise indicated) were prepared. Stoichiometric amounts of $\operatorname{Sr}\left(\mathrm{NO}_{3}\right)_{2}\left(>99.0 \%\right.$ Aldrich) and $\mathrm{Y}\left(\mathrm{NO}_{3}\right)_{3} \cdot 6 \mathrm{H}_{2} \mathrm{O}(99.8 \%)$ were dissolved in $20 \mathrm{ml}$ of de-ionised water under constant stirring in nitrogen atmosphere. This was followed by addition of $\mathrm{TiCl}_{3}$ solution $10 \mathrm{w} \%$ in $30 \% \mathrm{HCl}$ (Aldrich) and $\mathrm{ZrOCl}_{2}$ solution $30 \mathrm{w} \%$ in $\mathrm{HCl}$ (Aldrich). This mixture was added to a 2M solution of $\mathrm{NaOH}$. The precipitation was immediate and a clear separation between liquid and solids occurs within 1 hour. The crystal clear liquid was removed with a pipette and the precipitate centrifuged. To avoid re-dissolution of $\operatorname{Sr}(\mathrm{OH})_{2}$, the precipitate was then washed with a mixture of concentrated $\mathrm{NH}_{4} \mathrm{OH}$ and absolute ethanol and centrifuged again; this rinsing process was repeated five times.

To essay the possible re-dissolution of $\mathrm{Sr}$ in the rinsate concentrated $\mathrm{NaOH}$ was added to confirm that no precipitate was formed; $\mathrm{CO}_{2}$ was also bubbled into the rinsate to check for $\mathrm{SrCO}_{3}$ precipitation. The precipitate was further processed by drying in nitrogen atmosphere in a hot plate to eliminate the excess water.

The evolution of this precipitate was followed by thermogravimetry (TG) in air with a heating rate of $5^{\circ} \mathrm{C} \min ^{-1}$. Several batches of the powder were annealed at different temperature $\left(\mathrm{T}=400-1100{ }^{\circ} \mathrm{C}\right)$ for 1 hour and each sample was analysed by XRD (STOE Theta-Theta diffractometer) to observe the formation of the perovskite and the fluorite phases as well as to detect any possible reaction between them. The crystallite size was determined using Scherrer's formula and the lattice parameter with the 
embedded refinement in the Xwin XPOW software. The microstructure was studied with a scanning electron microscope (Zeiss, SUPRA 35 or LEO 1525).

\subsection{Consolidated samples}

The washed precipitate was calcined at $400^{\circ} \mathrm{C}$ for 1 hour, uniaxially pelletised and then isostatically compressed (195 MPa) at room temperature. The pellets were then heated $\left(300{ }^{\circ} \mathrm{C} \mathrm{h}^{-1}\right)$ in air up to $1100{ }^{\circ} \mathrm{C}$ for 1 hour. The density of pellets was measured with the Archimedes' method using deionised water as the immersion fluid. The structure development and microstructure were followed as a function of temperature by XRD and SEM, respectively.

A reference composite was prepared from commercial powders $\mathrm{SrTiO}_{3}$ (American Elements 99.9\%, $<100 \mathrm{~nm}$ ) and YSZ (Fuel Cell materials, 5-10 nm). The powders were milled overnight using zirconia balls and absolute ethanol. The dried powders were then treated exactly as the precipitated powders to obtain a consolidated body.

\subsection{Conductivity measurements}

An impedance analyser (Solartron 1260) was used to perform most of the measurements within the frequency range $0.1 \mathrm{~Hz}-1 \mathrm{MHz}$. Silver paint was applied on both faces of the pellets and baked at $400{ }^{\circ} \mathrm{C}$ in air for 1 hour before the measurements. The first set of measurements took place between 200 and $400{ }^{\circ} \mathrm{C}$ in air.

A second set of measurements was taken on a dense sample at a fixed temperature of $600{ }^{\circ} \mathrm{C}$ at different partial pressures of oxygen. A mixture of $\mathrm{H}_{2} \mathrm{O}$ and $\mathrm{H}_{2}$ was used to control the low $\mathrm{pO}_{2}$ region while for the high $\mathrm{pO}_{2}$ region, a mixture of air, $\mathrm{N}_{2}$ and oxygen was used. All the gases were controlled with flow meters while the $\mathrm{pH}_{2} \mathrm{O}$ was controlled by bubbling the gases in de-ionised water at $\mathrm{T}=14$ 
${ }^{\circ} \mathrm{C}$. In most cases the partial pressure of oxygen was tested ex-situ with a zirconia sensor at $\mathrm{T}=997$ ${ }^{\circ} \mathrm{C}$.

The impedance spectra were fitted using the routine embedded in the software ZsimpWin 3.21. The equivalent circuits selected are discussed in the corresponding section.

\section{Results and discussion}

\subsection{Strontium titanate}

\subsubsection{Microstructure}

Figure 1a shows the room temperature XRD patterns of powders and a pellet of $\mathrm{SrTiO}_{3}$ prepared by precipitation of metal hydroxides. $\mathrm{SrTiO}_{3}$ was obtained as a nanocrystalline phase at $400{ }^{\circ} \mathrm{C} ; \mathrm{SrCO}_{3}$ traces were observed but these were eliminated completely after $800^{\circ} \mathrm{C}$. No other phase was detected.

The microstructure of $\mathrm{SrTiO}_{3}$ nano-powders annealed at $400{ }^{\circ} \mathrm{C}$ and at $800{ }^{\circ} \mathrm{C}$ for 1 hour is seen in Figures $1 \mathrm{~b}$ and 1c, respectively. The powder in both cases consisted of spherical particles of ca. 200 $\mathrm{nm}$ in diameter. The crystallite size of all the annealed samples stayed around $37 \mathrm{~nm}$. At $800{ }^{\circ} \mathrm{C}$ the surface of the particles became smoother due to the decomposition of $\mathrm{SrCO}_{3}$, as observed comparing Figures $1 \mathrm{~b}$ and 1c, detected in the XRD (Figure 1a) and determined by the weight change in the TG experiments.

Figure $1 \mathrm{~d}$ shows a micrograph of fractured pieces of $\mathrm{SrTiO}_{3}$ sintered at $1100{ }^{\circ} \mathrm{C}$. The individual grains have a more faceted shape and did not undergo a large grain growth as can be seen by comparing the images in Figure 1. Na was observed by Energy-dispersive X-ray spectroscopy (EDS) to be distributed inhomogeneously with some regions reaching up to $3 \%$ in weight. It can be assumed that 
part of the excess Na substituted into the Sr sites, since their ionic radii are very similar: $\mathrm{Sr}^{2+}, 12-$ coordinated is $1.44 \AA$ while $\mathrm{Na}^{+}, 12$-coordinated is $1.39 \AA$ ); $\mathrm{Ti}^{4+}$ is too small to be substituted by ions such as $\mathrm{Na}^{+}$. Na then constituted an acceptor dopant and also led to a contraction of the lattice parameter of $\mathrm{SrTiO}_{3}$.

\subsubsection{Conductivity}

Figure 2a shows the impedance spectrum of a $\mathrm{SrTiO}_{3}$ pellet at $300{ }^{\circ} \mathrm{C}$. One clear semicircle was visible and fitted to a single Resistance-Constant Phase Element (R-CPE) parallel circuit corresponding to the bulk. The spectrum for $\mathrm{SrTiO}_{3}$ was similar to that reported for nanocrystalline un-doped $\mathrm{SrTiO}_{3}$ [11]. The conductivity $\sigma$ was thermally activated with an Arrhenius behaviour described by

$\sigma \mathrm{T}=1.17 \times 10^{7} \exp \left(-0.95 \mathrm{eV} / \mathrm{kb}_{\mathrm{b}} \mathrm{T} \mathrm{S} \mathrm{cm}^{-1} \mathrm{~K}\right.$

Eq. 1

Where $\mathrm{T}$ is temperature in Kelvin, and $\mathrm{k}_{\mathrm{b}}$ is the Boltzmann constant. The increased conductivity found in $\mathrm{SrTiO}_{3}$ in comparison with un-doped $\mathrm{SrTiO}_{3}$ must be related to the excess $\mathrm{Na}$ doping and the subsequent creation of oxygen vacancies, electron holes, or protons as compensating defects. These generation can be written respectively as:

$\mathrm{Na}_{2} \mathrm{O} \stackrel{\mathrm{SrTiO}_{3}}{\longrightarrow} 2 \mathrm{Na}_{\mathrm{Sr}}^{\prime}+\mathrm{V}_{O}^{*}+\mathrm{O}_{O}^{x}$

Eq. 2

$\mathrm{H}_{2} \mathrm{O}+\mathrm{V}_{\mathrm{O}}+\mathrm{O}_{O}^{x} \leftrightarrow 2 O H_{O}$

Eq. 3

$V_{O}^{\ddot{*}}+{ }_{2}^{1} O_{2} \leftrightarrow O_{O}^{x}+2 h$

Eq. 4

The conductivity of $\mathrm{SrTiO}_{3}$ can be greatly modified by small amounts of doping [12]. Protons are potential charge carriers due to the hydrophilic nature of $\mathrm{Na}$ [13] and the known capability of the 
$\mathrm{SrTiO}_{3}$ perovskite to incorporate water into its lattice $[14,15,16,17]$. Hole conductivity or oxygen ions are also expected to transport charge in $\mathrm{SrTiO}_{3}[12,18,19]$.

\subsection{Composites}

\subsubsection{Microstructure}

XRD patterns of the composite $\mathrm{SrTiO}_{3} / \mathrm{YSZ}$ powders annealed at different temperatures are shown in Figure 3a. Three main observations are:

1.- The dry precipitate obtained from the synthesis was mainly amorphous as seen at $400{ }^{\circ} \mathrm{C}$. The first compound to crystallise was $\mathrm{SrCO}_{3}$ but it disappeared completely at $800{ }^{\circ} \mathrm{C}$ according to $\mathrm{TG}$ and XRD.

2.- Complete crystallisation of the fluorite $\mathrm{YSZ}$ and the perovskite $\mathrm{SrTiO}_{3}$ took place between 500 ${ }^{\circ} \mathrm{C}$ and $600{ }^{\circ} \mathrm{C}$. No reaction between $\mathrm{YSZ}$ and $\mathrm{SrTiO}_{3}$ was observed up to $1100{ }^{\circ} \mathrm{C}$. This was also confirmed by the XRD of the reference sample i.e., the mixture of commercial powders, and seems in accord with the literature $[8,9,10]$.

3.- The lattice parameters of $\mathrm{SrTiO}_{3}$ and of $\mathrm{YSZ}$ change slightly in the presence of Na. See table 1. As observed by EDS there was Na in this batch, most likely incorporated into the $\mathrm{SrTiO}_{3}$ lattice at high temperature. Due to ionic radius mismatch in the sites of $\mathrm{Y}^{3+}$ (1.019 $\AA$, 8-coordinated), $\mathrm{Ti}^{4+}$ (0.605 $\AA$, six-coordinated) and $\mathrm{Zr}^{4+}$ (0.84 $\AA$, 8-coordinated), other doping sites were not considered, although $\mathrm{Ti}^{4+}$ can be incorporated into the $\mathrm{Zr}$ site in $\mathrm{YSZ}$. $\mathrm{Na}^{+}$ionic radii are $1.19 \AA$ for 8-coordination and $1.02 \AA$ for 6-coordination.

Table 1 shows the crystallite sizes, cell parameters, and relative densities of the different composites prepared here. The data of the IPDF files are included as a reference as well as the reference sample prepared from commercial nanopowders. 
No extra peaks were observed in the XRD pattern as seen in Figure 3a but according to the EDS some regions had up to 3\% weight in Na. The effect of the excess Na was observed in the XRD pattern as a change in the lattice parameter of $\mathrm{SrTiO}_{3}$ and not as a secondary phase. Samples with Na levels below the detection level of the EDS were prepared but did not achieve a good density.

Figure $3 \mathrm{~b}$ shows a micrograph of a precipitate treated at $800^{\circ} \mathrm{C}$ for 1 hour. The powder consisted of spherical particles of up to $200 \mathrm{~nm}$ in size. All particles seemed to show the same shape, topography, and contrast; at this stage there was no clear distinction between the fluorite and the perovskite phases.

Figure 3c and 3d show the structure of a composite with $88 \%$ of the theoretical density, the highest achieved for the composite pellets annealed at $1100{ }^{\circ} \mathrm{C}$. There was a clear microstructural characteristic: particles of ca. 0.7-0.8 $\mu \mathrm{m}$ in diameter and small particles $<50 \mathrm{~nm}$. Considering the low grain growth exhibited by $\mathrm{SrTiO}_{3}$ (see Figure 1d) and the calculation of the crystallite size (Table 1), the large particles can be assigned to YSZ and the small particles to $\mathrm{SrTiO}_{3}$. A relevant observation is the very good contact that exists between the grains and the consequent large interfaces between the YSZ and the $\mathrm{SrTiO}_{3}$, despite the presence of pores. Due to our interest in the interfacial transport, the conductivity of this sample was further studied in this work.

\subsubsection{Conductivity}

A typical impedance spectrum for a tested composite in air at $300{ }^{\circ} \mathrm{C}$ is shown in Figure $2 \mathrm{~b}$. It consisted of two signals with the highest frequency semicircle clearly defined. The symmetric Bruggeman model for inter-percolating phases in a composite was used to model the bulk conductivity [20]. The conductivity of the composite $\Psi_{\mathrm{m}}$ is

$\Psi_{m}=\frac{1}{4}\left\{q+\left(q^{2}+8 \Psi_{1} \Psi_{2}\right)^{\frac{1}{2}}\right\}$

Eq. 5

where 
$q=\left(3 x_{1}-1\right) \Psi_{1}+\left(3 x_{2}-1\right) \Psi_{2}$

Eq. 6

And $x$ is the volume fraction and the subindices indicate the phase.

A good fit to the experimental data is obtained only if the conductivity of each phase is smaller in the composite: a value of $\sigma=5 \times 10^{-7} \mathrm{~S} \mathrm{~cm}^{-1}$ was used for YSZ, as it decreases by ca. an order of magnitude when doped with $\mathrm{Ti}[21,22,23]$ and for a lightly acceptor doped $\mathrm{SrTiO}_{3}, \sigma=1 \times 10^{-7} \mathrm{Scm}^{-1}$ was used [24].

The bulk conductivities obtained from the high frequency semicircle for different samples are shown in Figure 4 as an Arrhenius plot. The results can be summarised as:

1.- The reference composite presented lower bulk conductivity than YSZ and high activation energy $\left(E_{a}\right)$, too high to be due to YSZ. There was no evidence of improved conductivity although the conductivity may be low because the sample was not very dense or YSZ was doped with Ti.

2.- The Na-doped composite presented a higher conductivity than the reference composite, a phenomenon associated with defect formation and transport (see Eq. 2-4).

3.- $\mathrm{SrTiO}_{3}$ showed the highest conductivity and could be clearly associated with Na doping. Since the $\mathrm{Na}$ in $\mathrm{SrTiO}_{3}$ is hygroscopic [13], this might suggest proton conduction. Proton conduction has been reported in Sc-doped $\mathrm{SrTiO}_{3}[14-17]$.

Figure 5 a shows an impedance plot of a tested composite in air at $600{ }^{\circ} \mathrm{C}$. At this temperature a scan of partial pressures of oxygen was performed; all the spectra were fairly similar. Three CPE-R elements were used to fit the spectra as shown in Figure 5a. The impedance of a CPE element is given by

$Z=\frac{1}{Y_{0}(j w)^{n}}$ 
Where $\mathrm{Y}_{0}$ is the admittance and $\mathrm{n}$ the exponential value obtained from the fitting of the CPE element [25]. To help in the assignation of the three signals observed, the equivalent capacitance $\mathrm{C}$ was estimated using

$C=\frac{\left(R_{0} Y_{0}\right)^{1 / n}}{R_{0}}$

Some information on the grain boundary can be obtained from the spectra measured at a fixed temperature of $600{ }^{\circ} \mathrm{C}$ and as a function of partial pressure of oxygen. The equivalent capacitances obtained from the three elements observed at $600{ }^{\circ} \mathrm{C}$ for all atmospheres are displayed in Figure $5 \mathrm{~b}$. The estimated equivalent capacitances can be used to identify the different elements in the impedance plots, namely bulk (ca $10^{-11} \mathrm{C} \mathrm{F}^{-1}$ ), grain boundary, (ca $10^{-8}$ and $10^{-9} \mathrm{C} \mathrm{F}^{-1}$ ) and electrode (ca $10^{-7} \mathrm{C}$ $\left.\mathrm{F}^{-1}\right)$

Figure 5c shows a plot of the resistance of bulk, grain boundary and electrodes as a function of $\mathrm{pO}_{2}$ for the $\mathrm{YSZ} / \mathrm{SrTiO}_{3}$ sample tested at $600{ }^{\circ} \mathrm{C}$.

In general, the bulk and grain boundary resistances did not seem to change dramatically with partial pressure of oxygen, although in the air-oxygen mixtures their values hinted at p-type behaviour at high $\mathrm{pO}_{2}$ and n-type at low $\mathrm{pO}_{2}$ as expected for $\mathrm{SrTiO}_{3}$ despite the scatter of data. The electrode response was clearly affected by the partial pressure of oxygen. No remarkable enhancement in the conductivity is seen in any of the fitted elements.

\section{Conclusions}

A method for the manufacture of sub-micrometric composites of SrTiO3-YSZ (1:1 volume) and samples of $\mathrm{SrTiO}_{3}$ was presented. No reaction between the components was seen but a change in the cell parameter of the $\mathrm{SrTiO}_{3}$ is attributed to the presence of Na. There is good interfacial contact 
between the phases in the consolidated composites $\mathrm{SrTiO}_{3}-\mathrm{YSZ}$ although they did not exhibit high levels of ionic conductivity in the grain boundary, nor in the bulk. The conductivity of Na-free composites is lower than the conductivity of pure YSZ while the conductivity of Na-doped composite samples was higher than non-doped composites. The composites did not exhibit high levels of ionic conductivity in the grain boundary nor in the bulk. The conductivity of single phase $\mathrm{SrTiO}_{3}$ exhibited an enhancement caused by Na doping. Charge transport is likely to be p-type, but it may be protonic in nature as in Sc-doped $\mathrm{SrTiO}_{3}$ and due to the hygroscopic nature of $\mathrm{Na}$ in $\mathrm{SrTiO}_{3}$.

\section{References}

1 J. Garcia-Barriocanal, A. Rivera-Calzada, M. Varela, et al. Science 321 (2009) 676.

2 X. Guo, Science 324 (2009) 465.

3 N. Schichtel, C. Korte, D. Hesse, J Janek. Phys. Chem. Chem. Phys. 11 (2009) 3043.

4 X. X. Guo, J. Maier, Adv. Mat. 21 (2009) 2619.

5 N. Sata, K. Eberman, K. Eberl, J. Maier; Nature 408 (2000) 946.

6 A. Cavallaro, M. Burriel, J. Roqueta, A. Apostolidis, A. Bernardi, A. Tarancón, R. Srinivasan, S. N. Cook, H. L. Fraser, J. A. Kilner, D. W. McComb, J.Santiso, Solid State Ionics 181 [13-14] (2010) 592-601.

7 R. A. De Souza and A. H. H. Ramadan, Phys. Chem. Chem. Phys.15 (2013) 4505.

8 Q. Ma, F. Tietz, D. Sebold, D. Stöver, J Power Sources 195 (2010) 1920.

9 B.R. Sudireddy P. Blennow, K.A. Nielsen, Solid State Ionics 216 (2012) 44.

10 B. Bochentyn, J. Karczewski, M. Gazda, P. Jasinski, B. Kusz, Phys. Status Solidi A 210 [3] (2013) 538.

11 P. Balaya, J. Jamnik, J. Fleig and J. Maier, Appl. Phys. Lett. 88 (2006) 062109.

12 R. A De Souza, Phys. Chem. Chem. Phys. 11 (2009) 9939.

13 A. Lopez, T. Heller, T. Bitzer. Q. Chen, N. V. Richardson, Surf. Sci. Lett. 494 (2001) L811. 
14 M. Widerøe, R. Waser, T. Norby Solid State Ionics 177 (2006) 1469.

15 S. Steinsvik, Y. Larring, Truls Norby, Solid State Ionics 143 (2001) 103.

16 N. Sata, K. Hiramoto; M. Ishigame, S. Hosoya, N. Niimura, S. Shin, Phys. Rev. B 54, 22 (1996) 15795-15799.

17 T. Onishi, T. Helgaker. Int. J. Quantum. Chem. 112 (2012) 201.

18 I. Denk, W. Münch, J. Maier, J. Am. Ceram. Soc. 78 (1995) 3265.

19 X. Guo J. Fleig, J. Maier Solid State Ionics 154-155 (2002) 563.

20 N. Bonanos, , B. C.H. Steele, E. P. Butler in E. Barsoukov, J. R. Macdonald (Eds.), Impedance Spectroscopy: Theory, Experiment, and Applications, 2nd Edition, John Wiley \& Sons, New Jersey, 2005 pp 221-223.

21 D.P. Fagg, J.R. Frade, M. Mogensen, J.T.S. Irvine, J. Solid State Chem. 180 (2007) 2371.

22 H. Naito, H. Arashi. Solid State Ionics 53 (1992) 436.

23 A. Kaiser, A. J. Feighery, D. P. Fagg, J. T. S Irvine, Ionics 4 (1998) 215.

24 R. A. De Souza, Adv. Funct. Mater. 25.40 (2015): 6326-6342

25 C. Hsu, F. Manfield, Corrosion 57 (21) 747. 
Table 1. Lattice parameters, crystallite size and percentage of theoretical densities. All composites were prepared at $1100^{\circ} \mathrm{C}$.

\begin{tabular}{|c|l|l|l|l|l|}
\hline & SrTiO $/ \AA$ & Crystallite & YSZ/A & Crystallite & theo. \\
& & size / nm & & size / nm & density \\
\hline IPDF file & 3,905 & & 5,1390 & & \\
\hline Reference SrTiO $/ Y S Z$ & 3,8979 & 40 & 5,1206 & 38 & 57 \\
\hline $\mathrm{SrTiO}_{3} / \mathrm{YSZ}$ (up to 3\%w Na) & 3,973 & $11^{a}$ & 5,134 & 44 & 88 \\
\hline $\mathrm{SrTiO}_{3}$ (up to 1\%w Na) & 3,8894 & 37 & ----- & ------ & 66 \\
\hline
\end{tabular}

${ }^{a}$ The crystallite of $\mathrm{SrTiO}_{3}$ is unusually small. Apparent broadening of the peak may be due to the presence of two similar $\mathrm{SrTiO}_{3}$ phases with different levels of $\mathrm{Na}$. 
Figure captions

Figure 1.a) $\mathrm{XRD}$ of $\mathrm{SrTiO}_{3}$ powders annealed at different temperatures. The sample at $1100{ }^{\circ} \mathrm{C}$ is a pellet. b). Micrograph of $\mathrm{SrTiO}_{3}$ powder annealed at $400{ }^{\circ} \mathrm{C}$ for 1 hour. The small grains observed on the surface of the spheres are $\mathrm{SrCO}_{3}$. c) Particles of $\mathrm{SrTiO}_{3}$ annealed at $800{ }^{\circ} \mathrm{C} . \mathrm{SrCO}_{3}$ is not detectable by XRD. A small amount of Na is observed by EDS. Note the smooth surface of the spheres and compare with those of $b . d$ ) A crushed sintered pellet of $\mathrm{SrTiO}_{3}$ with $66 \%$ of the theoretical density

Figure 2.a) Impedance spectrum in air at $300^{\circ} \mathrm{C}$ for $\mathrm{SrTiO}_{3}$. b) Impedance plot in air for a composite with $88 \%$ density at $T=300{ }^{\circ} \mathrm{C}$. Included is the result of the simulation using the symmetric Bruggeman model for a composite with inter-percolating materials [20].

Figure 3. a) $\mathrm{XRD}$ of $\mathrm{SrTiO}_{3} / \mathrm{YSZ}$ powders calcined for 1 hour at the temperature indicated. All samples were powders except sample at $1100{ }^{\circ} \mathrm{C}$ which is a pellet. b) Micrograph of a precipitate calcined at $800{ }^{\circ} \mathrm{C}$. c) SEM micrograph of a composite with $88 \%$ density. d). SEM Micrograph of the surface of a composite with excess $\mathrm{Na}$ (Some regions up to 3\% according to the EDS but no extra peaks were observed in the XRD.

Figure 4. Arrhenius plot for 2 different composites and Na-doped $\mathrm{SrTiO}_{3}$. The black line is the standard YSZ conductivity. Activation energy values: $1.19 \mathrm{eV}$ for the composite with commercial powders, 0.95 for $\mathrm{SrTiO}_{3}$ and $1 \mathrm{eV}$ for composite $\mathrm{YSZ} / \mathrm{SrTiO} \mathrm{O}_{3}$.

Figure 5. a) Impedance plot of composite at $\log (\mathrm{pO} / \mathrm{atm})=-27$ at $600{ }^{\circ} \mathrm{C} \mathrm{b}$ ) Capacitances of the three different elements observed in the impedance spectra as a function of $\mathrm{pO}_{2}$. From small to large equivalent capacitance the elements most likely represented are bulk, grain boundary and electrode respectively. c). Resistances of the 3 different elements observed in the impedance spectra. 